\title{
$\angle$ Research Square

\section{Assessment of food taboos and related misconceptions during pregnancy in Mekelle city, Tigray, Northern Ethiopia}

Freweini Gebrearegay Tela ( $\sim$ gebrearegayfreweini@gmail.com )

Mekelle University College of Health Sciences

Lemlem Weldegerima Gebremariam

Mekelle University College of Health Sciences

Selamawit Asfaw Beyene

Mekelle University College of Health Sciences

Research article

Keywords: Assessment, food taboos, pregnancy, Mekelle city, Tigray, Northern Ethiopia

Posted Date: September 25th, 2019

DOI: https://doi.org/10.21203/rs.2.14945/v1

License: (1) (i) This work is licensed under a Creative Commons Attribution 4.0 International License.

Read Full License 


\section{Abstract}

Introduction Communities, rural or urban, have their own taboos and misconceptions regarding what type of foods to consume and avoid during pregnancy and why. In Ethiopia, as in many other developing countries, there are misconceptions on specific quality and quantity of food a pregnant woman should or should not eat during pregnancy, affecting their nutritional status. Despite this, information related to food taboos in Ethiopia is lacking. Therefore, this study assessed food taboos and related misconceptions during pregnancy in Mekelle city, Tigray, Northern Ethiopia.

Method A cross-sectional study was conducted among 332 pregnant women who were in antenatal care follow-up in selected private clinics starting from January 1 st up to June/30/2017. A semi-structured questionnaire consisting of closed and open ended questions was prepared in the way that it can assess the food taboo practices, types of foods avoided, and the perceived reasons for avoidance. Data were entered in to SPSS version 21 for analysis. The results were described using frequency and percentage, and presented using tables. Cross-tabulation ( $x 2$ - test) was used to analyze the association between different socio-demographic variables and food taboo practice. Statistical significance was declared at $P$ -value $<0.05$ and $95 \%$ confidence interval $(\mathrm{Cl})$.

Result The results of this study indicate that $11.5 \%$ of the pregnant women avoided at least one type of food during their current pregnancy because of different perceptions. The mothers were forbidden from taking food items such as yogurt, banana, legumes, honey, "kollo" (roasted barley and wheat), and spices (mustard). The most common perceptions for the avoidance of these foods were abortion, abdominal cramp to the mother and newborn, prolonged labor, and coating to the body of the fetus. Among the socio-demographic characteristics studied, educational status was found to significantly influence food taboo practices among the study participants $(P<0.0001)$.

Conclusion The misconception on the feeding practice during pregnancy should be discouraged, and health providers should promptly counsel pregnant women about appropriate feeding practices during their ANC visits.

\section{Background}

The nutritional requirement of women increases during pregnancy, and restriction of certain food items rich in the required nutrients may lead to different consequences to the mother as well as to their growing fetus (1). Undernourished women are more likely to die during pregnancy, to give birth prematurely, and to have babies born prematurely or low birth weight (2). Newborns who suffer from fetal growth restriction due to poor maternal nutrition during pregnancy and who are lucky to survive are also at a substantially 
increased risk of being stunted during their childhood, eventually reducing their mental and physical capacity (2).

Adequate diet of a mother during pregnancy can be described as a healthy diet which contains adequate energy, fats, proteins, vitamins and minerals, which are obtained from consumption of a variety of food groups including whole grains, vegetables, fruits, legumes, milk, meat, fish, and nuts (3). In developing countries, where females usually don't have equal access to health care and education, maternal under-nutrition remains a major problem, and reduction of food intake among pregnant women, especially in the $2^{\text {nd }}$ and $3^{\text {rd }}$ trimesters is common (4); most pregnant women don't consume much food during these periods for the fear of big baby and difficult labor.

While adequate dietary intake during pregnancy could be affected by many factors including affordability and accessibility, food taboos have been reported as one of the main reasons pregnant mothers avoid intake of some foods which could negatively affect the nutritional status of the mothers and their growing fetus. Communities, whether rural or urban, have their own taboos and related misconceptions regarding what type of foods to eat during pregnancy and why. Feeding practices and consumption patterns vary from culture to culture as well as from society to society. Especially women are commonly refrained from eating certain food staffs for different reasons (5).

In Ethiopia, as in many other developing countries (6-9), there are food taboos and misconceptions on specific quality and quantity of food a pregnant woman should or should not eat during pregnancy, affecting their nutritional status $(10,11)$. A study in Shashemene district, Ethiopia, indicates that over half (65\%) of the pregnant women avoided at least one type of food as a result of food taboos and most of the food items that were avoided were: linseed, honey, milk and milk products, meat, egg, fruits and vegetables. Such foods were believed to be coated on the fetal body, lead to big baby causing difficult delivery, abortion, evil eye and fetal abnormality (12).

The fact that food taboos are closely linked to dietary intakes of pregnant women underscores the need and importance of assessing food taboos and related misconceptions 
during pregnancy for the installment of appropriate interventions at local, regional and national levels. However, the available literature indicate that little has been done on the issue; and information regarding these practices specifically in Tigray region is lacking. This study, therefore, assessed the food taboos and related misconceptions during pregnancy in Mekelle city, Tigray region.

\section{Methods}

\section{Study design}

A descriptive cross-sectional study was conducted to assess the range of food taboos and related misconceptions during pregnancy.

\section{Study area and period}

The study was carried out from April to May 2017 in five private clinics found in Mekelle city, capital of Tigray region which is located in the northern part of Ethiopia, at a distance of 783 Kilometers from Addis Ababa, the capital of Ethiopia. By the year 2016/17, the total population of Mekelle city was estimated to be 358,529 and the estimated number of pregnant mothers were 12,333. It has 1 comprehensive specialized hospital, 2 general hospitals, 9 health centers, and 12 known private clinics providing ANC services.

\section{Sources and study population}

All of the pregnant women attending their antenatal care (ANC) follow-up from the private clinics found in Mekelle city are considered as the target population, and those with ANC follow-up from the randomly selected clinics were the study population.

\section{Eligibility criteria}


All pregnant mothers who are permanent residents of Mekelle city, and who are over the age of 20 years were included whereas, mothers with hearing and speaking difficulty, and who were critically ill during the data collection period were excluded from this study.

\section{Sample size calculation}

The sample size was calculated using a single population proportion formula with the assumption of 95\% CI and 0.05 margin of error. Looking at the cross-sectional study done in Hadiya Zone, Northern Ethiopia, 27\% of the pregnant women practiced food taboos (11). Considering $P=27 \%$ from that study, the total sample size became 302 . We added $10 \%$ non-response rate, and the final sample size became 332.

\section{Sampling techniques}

Five clinics were selected randomly from the institutions with a better flow of pregnant women for ANC services. The number of study respondents was proportionally allocated to each clinic by considering the flow of pregnant women who had been served in the selected clinics in similar months of the previous year as a baseline. All pregnant women who came to these clinics for ANC service during the data collection period were taken consecutively until the sample size (332) was attained.

\section{Study variables}

The variables included in this study were: socio-demographic variables such as maternal age, religion, educational status, marital status, and occupational status; and nutritionrelated factors such as food taboos and related misconceptions, meal frequency when nonpregnant, meal frequency when pregnant, Women Dietary Diversity Score (WDDS), nutrition counseling, and fasting during pregnancy. 


\section{Data collection methods and tools}

A series of closed and open-ended questions were prepared by critically reviewing relevant literatures. The open-ended questions were prepared in the way that they can address the reasons why pregnant women avoid food items during their pregnancy. The questionnaire broadly incorporated information regarding socio-demographic characteristics, pregnancyrelated characteristics, and behavioral factors. Data were collected by trained midwives who work in the selected clinics.

Women Dietary Diversity Score (WDDS) was calculated from a single 24-hour dietary recall data. All foods and drinks that were consumed a day before the data collection were categorized into 10 food groups. A score of one was assigned for those who consumed a food item from any of the groups; if not, a score of zero was given. Then, a score out of 10 was computed by summing up the values of all the groups, and it was classified as achieved minimum diet diversity (MDD) ( $\geq 5$ ) and didn't achieve MDD (<5) (3).

\section{Data quality assurance}

To ensure the quality of data, a carefully designed data collection tool was prepared. Data collectors and supervisors were also trained for two days to have a common understanding of the overall purpose and methodology of the study. The questionnaire was pre-tested before the actual data collection, and modification was made thoroughly based on the pretest results. The questionnaire was translated into Tigrigna (local language), and then back-translated to English for ensuring the consistency of concepts. Supervisors were strictly following the data collection process for completeness of the questionnaires and any related support to boost the quality of the data. The data were checked and cleaned at the time of the data collection process and after data entry.

\section{Data management and analysis}


Data were entered into SPSS version 21 for analysis. The results were described using frequency and percentage. Finally results were presented using texts and table. Crosstabulation $\left(\mathrm{x}^{2}\right.$ - test) was used to analyze the association between the assessed sociodemographic variables and food taboo practice. Statistical significance was declared at $P$ value $<0.05$ and $95 \%$ confidence interval $(\mathrm{CI})$.

\section{Ethical consideration}

Ethical approval was obtained from the institutional review board (IRB) of the College of Health Sciences of Mekelle University, and permission was given by the private clinics to proceed the study. Informed verbal consent was taken from the study participants, and confidentiality was maintained throughout the study. The participants were well informed and guaranteed that they have the right to participate, refuse or stop at any time during the data collection process. The procedures of this study constituted a minimal risk to participants, and this was explained to them before the beginning of the data collection.

\section{Results}

\section{Socio-demographic characteristics of the study participants}

Almost all (98.8\%) of the study participants were from Tigray region, and all of them were residents of Mekelle city. The mean age of the pregnant mothers was 28.5 years, ranging from 20 to 38 years. The majority (85.3\%) of the participants were orthodox Christian followers. Regarding their educational status, more than half (56.6\%) of them were diploma and above (Table 1).

Table 1: Socio-demographic characteristics of the study participants $(n=332)$. 


\begin{tabular}{|c|c|c|c|}
\hline Variable & & Frequency & Percentage \\
\hline Age of the mother & $<30$ years & 198 & 59.6 \\
\hline & $\geq 30$ years & 134 & 40.4 \\
\hline Religion & Orthodox & 283 & 85.3 \\
\hline & Muslim & 39 & 14.7 \\
\hline & Others (Catholic and Protestant) & 10 & 3.0 \\
\hline Marital status & Single & 46 & 13.9 \\
\hline & Married & 282 & 84.9 \\
\hline & Widowed & 4 & 1.2 \\
\hline Educational level & Secondary education or below & 144 & 43.4 \\
\hline & Diploma and above & 188 & 56.6 \\
\hline Occupational status of the & mother & & \\
\hline & Student & 16 & 4.8 \\
\hline & Housewife & 112 & 33.7 \\
\hline & Government employee & 78 & 23.5 \\
\hline & Non-governmental employee & 45 & 13.6 \\
\hline & Self-employed & 81 & 24.4 \\
\hline Ownership of monetary re & Jurces Father & 130 & 39.2 \\
\hline & Mother & 23 & 6.9 \\
\hline & Both jointly & 179 & 53.9 \\
\hline Family size & $<4$ individuals & 179 & 53.9 \\
\hline & $\geq 4$ individuals & 153 & 46.1 \\
\hline Parity (No of childbirths) & Primipara (1 childbirth) & 117 & 51.8 \\
\hline & Multipara (1 - 4 childbirths) & 100 & 44.2 \\
\hline & Grand multipara ( $\geq 5$ childbirths) & 9 & 4.0 \\
\hline
\end{tabular}

\section{Nutrition-related characteristics of the study}

\section{participants}

The usual food consumed by $71 \%$ of the participants was enjera made of cereals (for example: teff, maize, and sorghum). The majority (91.6\%) of them eat three times a day before they become pregnant, and the rest of them eat four or more times a day. Regarding their meal frequency after they get pregnant, $68.1 \%$ of them eat four or more times a day. Almost two-thirds (65.1\%) of the participants fast (abstain from consumption of animal source foods) during pregnancy. Less than one-fourth $(20.8 \%)$ of the women achieved minimum diet diversity (MDD) (Table 2).

Table 2: Nutrition related characteristics of the participants $(n=332)$ 


\begin{tabular}{llll}
\hline Variable & Category & Frequency & Percentage \\
\hline Meal frequency when non-pregnant & 3 times & 304 & 91.6 \\
& $\geq 4$ times & 28 & 8.4 \\
\hline Meal frequency when pregnant & 3 times & 106 & 31.9 \\
& $\geq 4$ times & 226 & 68.1 \\
\hline Nutrition counseling received & Yes & 86 & 25.9 \\
& No & 246 & 74.1 \\
\hline Fasting during pregnancy & Yes & 216 & 65.1 \\
& No & 116 & 34.9 \\
\hline WDDS & Achieved MDD & 69 & 20.8 \\
& Didn't achieve MDD & 263 & 79.2 \\
\hline
\end{tabular}

\section{Food taboos and related misconceptions during}

\section{pregnancy}

Thirty eight (11.5\%) of the participants avoided at least one type of food during their current pregnancy for different reasons. Legumes were reported as taboo foods by $45.7 \%$ of the pregnant mothers who practiced food taboo. Furthermore, 22\%, 15.8\%, 13.2\%, $10.5 \%, 8.1 \%$, and $8 \%$ of the pregnant women avoided mustard, porridge, banana, whole grain in the form of "kollo", honey, and milk products (yogurt and milk) respectively.

The most common reasons for avoiding legumes (beans, and chickpea) were because they are believed to cause abdominal cramp, prolongs labor and exacerbates labor pain to the mother, and cause abortion, and abdominal cramp to the fetus. Similarly, whole grains in the form of "kollo" were believed to exacerbate labor pain, and cause postpartum abdominal cramp, heartburn, and nausea to the mother. Porridge, banana, and milk products were also avoided by some mothers because of the perception that they are coated to the body of the fetus and makes the baby very big causing difficult/prolonged labor. Honey was also considered as taboo by some respondents because of the perception that it causes abortion, and exacerbates labor pain. Mustard was also perceived by some mothers to cause abortion (Table 3).

Table 3: Foods avoided during pregnancy by the study participants and their reasons $(n=38)$ 


\begin{tabular}{|c|c|c|}
\hline $\begin{array}{l}\text { Type of food } \\
\text { taboo }\end{array}$ & $\begin{array}{l}\text { Frequency } \\
\text { (\%) }\end{array}$ & Reasons for the avoidance of these food items \\
\hline $\begin{array}{l}\text { Legumes } \\
\text { (beans, and } \\
\text { chickpea) }\end{array}$ & $\begin{array}{l}16 \\
(45.5 \%)\end{array}$ & $\begin{array}{l}\text { Causes abdominal cramp and prolongs labor, and } \\
\text { exacerbates labor pain, and abdominal cramp to the fetus, } \\
\text { and causes abortion }\end{array}$ \\
\hline Mustard & $8(22 \%)$ & Causes abortion and abdominal cramp to the newborn \\
\hline Porridge & $6(15.8 \%)$ & $\begin{array}{l}\text { Coated to the body of the fetus and makes the baby very } \\
\text { big causing difficult labor }\end{array}$ \\
\hline Banana & $5(13.2 \%)$ & $\begin{array}{l}\text { Coated to the body of the fetus, makes the baby very big } \\
\text { causing difficult labor }\end{array}$ \\
\hline $\begin{array}{l}\text { "Kollo" } \\
\text { (roasted wheat } \\
\text { and barley) }\end{array}$ & $4(10.5 \%)$ & $\begin{array}{l}\text { Causes postpartum abdominal cramp, heartburn, nausea, } \\
\text { and exacerbates labor pain }\end{array}$ \\
\hline Honey & $3(8.1 \%)$ & Causes abortion and exacerbates labor pain \\
\hline Yogurt and milk & $3(8.1 \%)$ & $\begin{array}{l}\text { Coated to the body of the fetus, and makes the baby very } \\
\text { big causing difficult labor }\end{array}$ \\
\hline
\end{tabular}

\section{Socio-demographic factors associated with food}

\section{taboos during pregnancy}

Educational status of the mother was found to be a significant factor associated with food taboo practice. Pregnant women whose educational status is lower than $12^{\text {th }}$ grade are more likely to practice food taboo during pregnancy compared to those who are diploma and above $(p<0.0001)$. Other than educational level, there is no significant association between the other independent variables and food taboo practice (Table 4).

Table 4: Cross-tabulation between the socio-demographic factors and food taboos practice 


\begin{tabular}{|c|c|c|c|c|}
\hline \multirow[t]{2}{*}{ Variables } & \multirow[t]{2}{*}{ Categories } & \multicolumn{2}{|c|}{$\begin{array}{l}\text { Taboos/ } \\
\text { misconceptions }\end{array}$} & \multirow[t]{2}{*}{$P$-value } \\
\hline & & $\begin{array}{l}\text { No: } n \\
\text { (\%) }\end{array}$ & $\begin{array}{l}\text { Yes: } n \\
\text { (\%) }\end{array}$ & \\
\hline \multirow[t]{2}{*}{ Age } & $<30$ years & 173 & $25(12.6)$ & 0.261 \\
\hline & $\geq 30$ years & $\begin{array}{l}121 \\
(90.3)\end{array}$ & $13(9.7)$ & \\
\hline \multirow[t]{3}{*}{ Religion } & Orthodox & $249(88)$ & $34(12)$ & \\
\hline & Muslim & 37 (95) & $2(5)$ & 0.309 \\
\hline & Protestant & $8(80)$ & $2(20)$ & \\
\hline \multirow[t]{3}{*}{ Marital status } & Single & $\begin{array}{l}44 \\
(95.7)\end{array}$ & $2(4.3)$ & \\
\hline & Married & $\begin{array}{l}246 \\
(87.2)\end{array}$ & $36(12.8)$ & 0.193 \\
\hline & Widowed & $4(100)$ & 0 & \\
\hline \multirow[t]{2}{*}{ Educational level } & $\begin{array}{l}\text { Secondary education or } \\
\text { below }\end{array}$ & $\begin{array}{l}117 \\
(81.2)\end{array}$ & $27(18.8)$ & $<0.0001$ \\
\hline & Diploma and above & $\begin{array}{l}117 \\
(94.1)\end{array}$ & $11(5.9)$ & \\
\hline \multirow[t]{5}{*}{$\begin{array}{l}\text { Occupational status of the } \\
\text { mother }\end{array}$} & Student & $\begin{array}{l}15 \\
(93.8)\end{array}$ & $1(6.3)$ & \\
\hline & Housewife & $\begin{array}{l}96 \\
(85.7)\end{array}$ & $16(14.3)$ & \\
\hline & Government employee & $\begin{array}{l}70 \\
(89.7)\end{array}$ & $8(10.3)$ & 0.644 \\
\hline & $\begin{array}{l}\text { Non-governmental } \\
\text { employee }\end{array}$ & $\begin{array}{l}42 \\
(93.3)\end{array}$ & $3(6.3)$ & \\
\hline & Self-employee & $\begin{array}{l}71 \\
(87.7)\end{array}$ & $10(12.3)$ & \\
\hline \multirow[t]{3}{*}{ Ownership of money } & Father & $\begin{array}{l}111 \\
(85.4)\end{array}$ & $19(14.6)$ & \\
\hline & Mother & $23(100)$ & 0 & 0.112 \\
\hline & Both jointly & $\begin{array}{l}160 \\
(89.4)\end{array}$ & 19 (10.6) & \\
\hline \multirow[t]{2}{*}{ Fasting during pregnancy } & Yes & $\begin{array}{l}101 \\
(34.4)\end{array}$ & $15(39.5)$ & 0.589 \\
\hline & No & $\begin{array}{l}193 \\
(65.6)\end{array}$ & $23(60.5)$ & \\
\hline
\end{tabular}

\section{Discussion}

This study was aimed at assessing food taboos and related misconceptions during pregnancy in Mekelle city, Tigray, northern Ethiopia. Like other regions of the country $(10,11)$, food taboos and related misconceptions influence the dietary practice of pregnant women in the study area; thus, $11.5 \%$ of the participants avoided at least one type of food 
during their current pregnancy for different reasons. The prevalence of food taboos observed in this study appears to be relatively lower when compared to the reports elsewhere in Africa and Ethiopia $(10,11,13-15)$. This lower prevalence might be because this study was conducted in private clinics, and the participants have relatively better educational status in which more than half of them were diploma and above. The fact that all of the study participants in this study are urban (Mekelle city) residents might also improve their awareness of feeding during pregnancy.

The common food items avoided by pregnant women in this study were legumes, porridge, banana, honey, mustard, and whole grains in the form of "kollo" for different reasons. Many literatures also showed that many women refrain from eating a variety of nutritious food items during pregnancy for different reasons. A study conducted among rural women of Surendranagar district showed that women commonly avoid fruits such as papaya, ground nut and citrus foods for the perception that they can cause abortion, placental disruption and difficult labor during pregnancy (13). A study among rural women of Aligarh also revealed that most of the pregnant women in the community avoid papaya, fish, citrus foods, and ground nut for the reasons that they can cause abortion, placental abruption, itching, and seizure (16).

It is obvious that food taboos, and related misconceptions of pregnant women can negatively affect their nutrition and health status as well as the health and future life of their growing baby $(2,17)$. In this study, pregnant mothers were prohibited to consume food items such as whole grains in the form of "kollo", and legumes such as beans and chickpea because they are believed to cause abdominal cramp during labor to the mother, prolong labor, and cause abdominal cramp to the newborn. Avoidance of such whole grains and legumes may negatively affect the dietary intake of these women, and this contradicts with the women dietary diversity recommendation of pregnant women (3). This also contradicts with the fact that whole grains, wheat bran or other high fiber foods, are used to relieve constipation in pregnancy, and legumes can provide high quality protein when they are complemented by whole grain containing foods. 
Pregnant women were also refrained to eat animal source foods such as milk and yogurt which are rich in high quality (complete) proteins (18). This were similar with a study conducted in Hadiya Zone, Ethiopia which revealed that pregnant women were restricted from eating milk and cheese for the fear of difficult labor and delivery (11). A similar in Sudan also revealed that $41.5 \%$ the pregnant women were refrained from drinking milk (15). This might lead the pregnant women to poor weight gain, and giving birth to low birth weight baby. Moreover, low consumption of animal source foods during pregnancy could also deprive them from different essential nutrients leading them to protein, energy, and micronutrients deficiency as protein-rich foods are also good sources of calcium, iron, and vitamin B-complex (19).

Banana was also considered as a food taboo by some of the study participants for the reason that it can be coated to the body of the fetus and leads the baby to be very big causing difficult labor. This was in line with a study in Shashemene, Ethiopia which revealed that pregnant women were restricted from eating fruits (10). This contradicts with the fact that banana is rich in potassium which can improve the health of the heart of the mother as well as her growing fetus. Banana also contains many other micronutrients such as vitamin $B_{6}$, minerals, fiber and can also serve as an antioxidant (20).

Pregnant women were also restricted to eat honey because of the fear that it can cause abortion and exacerbates labor pain. This was in line with a study conducted in Shashemene, Ethiopia which revealed that honey was restricted by pregnant women for the perception that it can cause abortion (10). Despite this, it has been scientifically proved that honey contains higher amount of carbohydrates, proteins, minerals, and different antioxidants (21).

This study showed a significant association between food taboo practice among pregnant women and their level of education $(\mathrm{p}<0.0001)$. This was in line with a study in Sudan which revealed that there was a significant association between food taboo practice during pregnancy and their educational level (15). A similar study in Nigeria and Sudan also showed a significant association between food taboo practice and educational status 
$(15,22)$ A study conducted in Shashemene district, Ethiopia also revealed that those women with higher educational level are less likely to practice food taboo during pregnancy than their counterparts (10). This might be due to the knowledge that they gained from formal education and from reading which may simultaneously boost their healthy eating practice.

As a strength of the study, recall bias was also reduced because the pregnancy-related information was collected at the time of pregnancy. Being a cross-sectional study may be considered as a limitation of this study, and it may be better to further investigate the effect of food taboos on the maternal nutritional status, and on pregnancy outcomes using better study designs, for example, using cohort study. It was also better if the study covered a wider area including the rural communities for better generalization of the result.

\section{Conclusions}

Adherence to cultural food beliefs is still evident in pregnant women found in Mekelle city. Educational status was a significant factor negatively associated with food taboo and related misconceptions. Thus, there is a need for nutrition education and awareness creation for pregnant women during their ANC follow-up.

\section{Abbreviations}

ANC

CI

MDD-W

IRB

SPSS

WDDS

\section{Declarations}

Antenatal Care

Confidence Interval

Minimum Diet Diversity of Women

Institutional Review Board

Statistical Package for Social Science

Women's Dietary Diversity Score 


\section{Ethics approval and consent to participate}

Before the study was conducted, an ethical approval was obtained from the institutional review board (IRB) of the College of Health Sciences of Mekelle University, and permission was given by the private clinics to proceed the study. The ethics committee approved the use of verbal consent, and informed consent was taken from the study participants. Written consent is not applicable to this research design.

\section{Consent for publication}

Not applicable

\section{Availability of data and materials}

All data supporting the results are available with in this manuscript.

\section{Competing interests}

All of the authors declare that they have no competing interests.

\section{Funding}

Not applicable

\section{Authors' contributions}

All of the authors, FGT, LW, and SA were involved in the proposal writing, designing recruitment and training of supervisors and data collectors, analysis as well as write-up of 
the manuscript. Finally, all authors have read and approved the manuscript.

\section{Acknowledgment}

The authors would like to acknowledge all of the respondents for their information, and we also thank the administrative bodies of the clinics for allowing as to collect this information from their institutions.

\section{References}

1. USAID. Addressing Barriers to Maternal Nutrition: Evidence and Program Considerations April. 2017;(April):1-9.

2. Khanna SB, Dash K, Dwivedee K. Fetal Origin of Adult Disease. JK Sci. 2007;9(4):20610.

3. FAO. Guidelines for measuring household and individual dietary diversity. Fao. 2010. 1$60 \mathrm{p}$.

4. Hutter I. Reduction of food intake during pregnancy in rural. Trop Med Int Heal. 1996;I(3):399-405.

5. Gadegbeku C, Wayo R, Badu GA, Nukpe E, Okai A. Food taboos among residents at Ashongman - Accra , Ghana. 2013;15:21-30.

6. Otoo P, Habib H, Ankomah A. Food Prohibitions and Other Traditional Practices in Pregnancy: A Qualitative Study in Western Region of Ghana. Adv Reprod Sci. 2015; (August):41-9.

7. Sholeye OO, Badejo CA, Jeminusi OA. Dietary habits of pregnant women in Ogun-East Senatorial Zone, Ogun State, Nigeria : A comparative study. 2014;6(4):42-9.

8. Koirala AK. Mothers ' Behaviors in Relation to Pregnancy and Childbirth in Kathmandu , Nepal-A Hospital Based Study. J Pregnancy Child Heal. 2018;5(5):10-4. 
9. Arzoaquoi SK, Essuman EE, Gbagbo FY, Tenkorang EY, Soyiri I, Laar AK. Motivations for food prohibitions during pregnancy and their enforcement mechanisms in a rural Ghanaian district. J Ethnobiol Ethnomed. 2015;1-9.

10. Biza N. Food Taboos and Misconceptions Among Pregnant Women of Shashemene District ,. Sci J Public Heal. 2016;(September).

11. Demissie T, Muroki N, Kogi-makau W. Food taboos among pregnant women in Hadiya. Ethiop J Heal Dev. 1998;12(1):45-9.

12. Nejimu Biza Zepro. Food Taboos and Misconceptions Among Pregnant Women of Shashemene District ,. Sci J Public Heal. 2016;(September).

13. Parmar A, Khanpara H, Kartha G, Resident PG, Shah CU. A study on taboos and misconceptions associated with pregnancy among rural women of Surendranagar district 1. pISSN. 2013;4(2):2-5.

14. Uzma Eram, Tamanna, Z., Humaira J. Taboos and misconceptions associated with pregnancy among rural. IJIRR. 2016;03:3407-9.

15. Hadil Mohamed Hassan Tahir1, Dr. Abd Elbasit Elawad Mohammed Ahmed2 DNAAM, 1MSc. Food Taboos among Pregnant Women in Health Centers, Khartoum StateSudan. 2018;3(March):13-25.

16. Uzma Eram, Tamanna, Z., Humaira JT. Taboos and misconceptions associated with pregnancy among rural. 2016;03:3407-9.

17. Pitale DL. The effects of food habits on pregnancy outcome. 2018;7(2):622-7.

18. Hoffman JR, Falvo MJ. Review article protein which is best? 2005;(2004):118-30.

19. Murphy SP, Allen LH. Animal Source Foods to Improve Micronutrient Nutrition and Human Function in Developing Countries Nutritional Importance of Animal Source Foods 1. 2003;3932-5.

20. Someya S, Yoshiki Y, Okubo K. Antioxidant compounds from bananas ( Musa Cavendish ). 2002;79:351-4.

21. Escuredo O, Fernández-gonzález M, Seijo MC. Nutritional value and antioxidant activity of honeys produced in a European Atlantic area. Food Chem. 2013;138(2-3):851-6. 
22. Oni OA, Tukur J. Identifying pregnant women who would adhere to food taboos in a rural community : a community-based study. 2012;16(September):67-75.

\section{Supplementary Files}

This is a list of supplementary files associated with this preprint. Click to download.

- Questionniarefordatacollection.docx 